ERRATA

\title{
Erratum to: Effect of Tannin on Compound Collector Adsorption and Stibnite and Arsenopyrite Flotation from Complex Ore
}

\author{
T. N. Matveeva*, N. K. Gromova, and L. B. Lantsova
}

IPKON, Russian Academy of Sciences, Moscow, 111020 Russia

*e-mail:tmatveyeva@mail.ru

Received November 8, 2017

DOI: $10.1134 / \mathrm{S} 1062739118033965$

ACKNOWLEDGMENTS should read:

This study was supported by the Russian Foundation for Basic Research, project no. 16-05-00646a.

The original article can be found online at https://oi.org/10.1134/S1062739117063197. 